\title{
Nature, dwelling. A needed new balance
}

\author{
Naturaleza, habitar. Un nuevo balance necesario
}

\author{
Roberto Pasini $i^{*}$, ๑ https://orcid.org/0000-0002-9011-2908
}

Citar este artículo como: Pasini, R. (2020). Nature, dwelling. A needed new balance. Revista Nodo, 15(29), pp. 8-19.

\section{Abstract}

This text reviews the current state of nature on the planet and the anthropogenic causes of the incumbent ecological crisis. In the first part, the paper illustrates a set of essential principles on which the understanding of the ecologic functioning on the micro and macro-scale relies. In the second part, it elaborates on the cultural and societal forms of the human presence on the planet, discussing the divarication sundering dwelling from the natural subsistence of animals and plants. The methodology adopted is the compared analysis of two thematic bibliographies, on the one hand, interpreting landscape as an ecological apparatus, on the other hand, as a product of human culture and society. The combination of opposite but coexisting perspectives allows linking the disruptions of the metabolic regime of the biosphere to the anthropic act of dwelling. In light of a third thematic bibliography photographing the state of the biosphere, the conclusions propose an agenda consisting of six imperatives relative to the spheres of cognition, demography, economy, equality, ecology, and built environment, meant to revert the ongoing ecological crisis on the planet and regain a new nature/dwelling balance.

Keywords: Biodiversity, Ecosystem services, Agriculture, Urbanization, Socio-economic system.

\section{Resumen}

Este texto revisa el estado actual de la naturaleza en el planeta y las causas antropogénicas de la crisis ecológica en proceso. En la primera parte, el documento ilustra un conjunto de principios esenciales en los cuales se basa la comprensión del funcionamiento ecológico en la escala micro y macro. En la segunda parte, trata de las formas culturales y sociales de la presencia humana en el planeta, articulando la divergencia entre el habitar y la subsistencia natural de animales y plantas. La metodología adoptada es el análisis comparado de dos bibliografías temáticas, por un lado, interpretando el paisaje como un aparato ecológico y, por otro lado, como un producto de la cultura y la sociedad humana. La combinación de perspectivas opuestas pero coexistentes permite vincular las rupturas del régimen metabólico de la biosfera con la acción antrópica del habitar. A la luz de una tercera bibliografía temática que refleja el estado de la biosfera, las conclusiones proponen una agenda que consta de seis imperativos relativos a las esferas de la cognición, demografía, economía, igualdad, ecología y medio ambiente construido, dirigidos a revertir la actual crisis ecológica en el planeta y recobrar un nuevo balance naturaleza/habitar.

Palabras clave: Biodiversidad, Servicios de ecosistemas, Agricultura, Urbanización, Sistema socio-económico.

Fecha de recepción: 4 de junio de 2020 • Fecha de aceptación: 3 de agosto de 2020

\footnotetext{
* Doctor en Arquitectura y Urbanismo. Profesor titular de Arquitectura y Ciencias del Hábitat, Universidad de Monterrey, México. Correo electrónico: aus.pasini@gmail.com
} 


\section{Introduction}

The notion of landscape and its metabolism have become central in the broader discourse of the design disciplines. Our contemporary landscape is natural and artificial. Humankind has first expanded its artifacts over nature and now seeks to bring back nature into its artificial platforms of dwelling, megaregional agglomerations that once were cities, fields, and wilderness. All animals live in nature; humans dwell. Animal populations are subject to autoregulatory laws, move following cycles. By technique, humans enjoy the emancipation from some hazards, rest and dwell. Following the proliferation of humankind in the industrial age, the persistence of parasitic models of depredating, consuming, and disposing of natural resources has brought forth a dramatic collapse of the planetary metabolism. The human system has overgrown to the point of tilting its thermodynamic balance with the exterior environment. Today, dwelling is at odds with nature. The Earth has experienced prior catastrophes, exhibiting the capacity to regenerate itself into new natural orders. Humankind might pay the toll of its behaviors. This paper first reviews a set of elemental principles describing the metabolic functioning of natural ecologies propaedeutic to the disciplinary debate on space planning, designing, and making. It then describes the disruptions recently produced by human activities relative to the primordial act of dwelling. Finally, it proposes an agenda of six urgent imperatives to ensure a future for humankind.

\section{Part 1. Nature: structure and functioning of landscapes}

\section{Biodiversity and heterogeneity}

We know that the diversity of fauna species on an island depends on the colonization and extinction rates that propagate or curtail each relative population. In the late '60s, biologists were able to link fauna diversity to simplified factors reckoning for more complex dynamics governing colonization and extinction phenomena. Stating that fauna diversity on an island is, by first approximation, a function of its size and distance from the mainland, the Island Biogeography Theory would enjoy widespread popularity. In general terms, an island is populated by flows of individuals reaching its shore from the mainland. Then, the island population goes through colonization and extinction dynamics in a condition of partial isolation, where proximity of other islands should also be considered. In a scenario of population growth, flows can depart in search of resources and colonize another island. In a scenario of population decrease due to stochastic occurrences, rescue flows of new individuals can arrive from the mainland or another island (Collinge, 2009, pp. 22-24).

What we have just described is a piece of oceanic geography assimilable to any fragmented landscape whose distant patches are connected by improbable but occurring flows. If we observe a terrestrial landscape from above, in fact, we can usually recognize uniform patches standing out against the background of an undefined, heterogeneous matrix, just like the outlines of islands stand out against the background of the ocean.

For both an ocean island and a landscape patch, the sharpness or blurriness of the edge is scaledependent. A definite perimeter traced along the shores of an island as well as the outline of a consistent landscape patch stand for a transition belt, whose width could be observed on a larger scale. However, we could think of the uniform landscape patch identified on a coherent scale as the habitat of specific populations, just like it is for an island.

As recurrent in traditional biology, the distinction between population and habitat, here, refers to, respectively, fauna and the ensemble of abiotic platform and flora. ${ }^{1}$ On the one hand, the back-

1 Only recently, the distinction between individual and background (in other words, population and habitat) 
ground matrix of the ocean is an almost neutral medium separating population habitats. On the other hand, a generic landscape matrix only exhibits relative neutrality. In this latter case, a certain degree of structuration of the matrix, that is, a set of formal and functional conditions, determines a specific context surrounding the patch. For the basic Island Biogeography Theory to successfully apply to the study of terrestrial landscapes and their fauna diversity, some additional variables relative to those contextual conditions ought to be introduced.

The more general notion of degree of isolation of a patch can replace the idea of distance from the dominating chunk of homologous habitat, be it the mainland for offshore geographies or the mother habitat for terrestrial landscapes. By evaluating the degree of isolation, the analysis can incorporate the presence of other interacting patches around the analyzed patch and the relative spatial structuration that converts the surrounding matrix into a context. From this simple consideration, descends a formulation consolidating the disciplinary basis of landscape ecology in the '90s: fauna diversity in a patch is the function of its degree of isolation and size, as well as of the structuration of the surrounding matrix. Existing external disturbances, age of the patch, which position it along the evolution line of its natural succession, as well as the internal articulation of the habitat play a role (Forman, 1995, pp. 62-63, 80). In a landscape ensemble composed of geogenic elements and dynamics, the term 'disturbances' incorporates the possible

has been linked to the relativity of the observation point, beyond the traditional fauna and flora divide. In this sense, the term 'individual' could even refer to a patch, whose background corresponds to the overall matrix. In the frame of the contemporary eco-field paradigm (Farina, 2009, pp. 108-110), the role of individual and background can be interchangeable between any living agents regardless of their belonging to the animal or the vegetal world. Researchers have even attributed forms of cognitive agency to inanimate formations or processes, such as hydrogeologic flows (Couper, 2007). impacts of anthropogenic activities. By internal 'articulation' and external 'structuration', we refer to a level of ordered complexity respectively inside the patch and in the surrounding matrix that redeems a homogeneous random distribution. In landscape ecology, articulation and structuration are commonly termed heterogeneity.

Extending the sense of the previous formulations in a contemporary perspective, we could affirm that flora and fauna biodiversity within a landscape patch is the function of its isolation, size, internal articulation, age, external disturbances, and structuration of the surrounding matrix. Biodiversity within a spatial region, then, corresponds to the intensity of the life forces that cross it to organize a distinct order in evolving equilibrium and keep it from falling into undifferentiated chaos.

\section{Spatial structure and ecologic metabolism}

From the considerations drafted above on biodiversity, we can derive an understanding of the contemporary landscape useful and wieldy to the ones operating in the disciplines of space design. According to this model, any landscape can be envisioned as a mosaic formed by components of three types only, namely patch, corridor, and matrix, whose determination is scale-dependent ${ }^{2}$ (Forman, 1995, pp. 3-7). By plunging into a landscape from the sky, one distinguishes an infinite series of patch-corridor-matrix mosaics, changing at every moment with view point and scale, and eventually lands without exception either onto a patch, a corridor, or a matrix.

As already mentioned, the patch is the elemental delimitation containing a characterized environment, which we can identify with a coherent ecosystem. An ecosystem is an ensemble of biotic

2 The patch-corridor-matrix landscape model constitutes one of the disciplinary foundations of landscape ecology, a field that Richard T.T. Forman had started conceiving since the late '70s in correspondence with Michel Godron (Barrett et al., 2015, p. 17). 
and non-biotic components interacting through flows of energy, matter, information, and individ$u^{u a l s}{ }^{3}$. The nutrient cycles of an ecosystem convert substances over multiple phases tending to an evolving equilibrium within a spatially determined boundary. Directional flows of energy and inputs and outputs of matters and heat through the system boundary define the relationship of the ecosystem with the external world. The delimitation of the boundary depends on the scale and the vantage point. Flows and cycles characterize the metabolism of the ecosystem. The analysis of an ecosystem is usually operated by defining an interpretative duality, contrasting an observed subject with a supporting platform. The subject is often the fauna population with its abiotic and floral habitat as its support. However, in more general terms, living organisms stand in contrast with an abiotic environment.

The flows of individuals that cross the waters to reach an ocean island from the mainland seem to break new paths over the surface of a blank medium. However, those paths might be routes predetermined by the course of oceanic currents. Preferred routes cross the matrix of terrestrial landscapes alike, due to the formal and functional articulation of its structure. In consideration of a minor permeability of the rest of the matrix, such corridors channel the most considerable part of the flows between homologous patches.

Describing the matrix, we have referred to formal and functional articulations to denote, respectively, the spatial configuration and the working metabolism of its structure. Spatial configuration unfolds in visible forms while working metabolism performs processes. Spatial configuration and working metabolism entertain an in-depth, either hidden or exposed, correspondence. The formal and functional character

3 Ecosystem ecologists calculate a number of individuals in terms of their overall biomass to formulate balance equations and input-outputs models. In contrast, population and community ecologists avoid this practice as an excess of abstraction (Fath, 2009, p. 6). of the surrounding matrix not only affects the ecological dynamics outside the patches, as we have seen above, but also the internal metabolism of the patches. The character of a specific contextual matrix determines effects on the edge of the patches by allowing or preventing the occurrence of phenomena alien to the patch metabolism. The impact of such phenomena extends inwards beyond the edge of the patch, for a depth varying according to several factors. This edge effect brings the character of the matrix inside the patches.

In general terms, there exist an overall correspondence between the spatial configuration of a landscape that we term mosaic and its functioning metabolism that we term ecosystem, that is, form and process. This correspondence involves the totality of the landscape components and their organization. We could regard a certain spatial structure as the product of processes that have occurred over time. Likewise, certain metabolic processes are induced or directed by a specific spatial structure (Forman, 1995, p. 5).

The functioning of ecosystems resonates in the landform of their spatial compounds and vice versa: ecologic metabolism and socio-cultural figuration of land are inextricable. To visualize the landscape mosaic model, we have diagrammed an ensemble of patch, corridor, and matrix on a portion of the 'Willem Lodewijk van Nassau Kazerne' image from the Dutch Landscapes series of 2011 (see Figure). The series is a set of frames of Google satellite imagery selected by visual artist Mishka Henner. Here, colorful Voronoi patterns imposed by the Dutch government to censor national-security-sensitive sites stand alongside the physical alterations of the natural landscape due to the land reclamation of the polders ongoing since the $16^{\text {th }}$ century (Henner, 2011). The presented figure illustrates the reciprocity of form and process vis-à-vis both natural and socio-cultural forces acting on land, about which we will extend further ahead. 


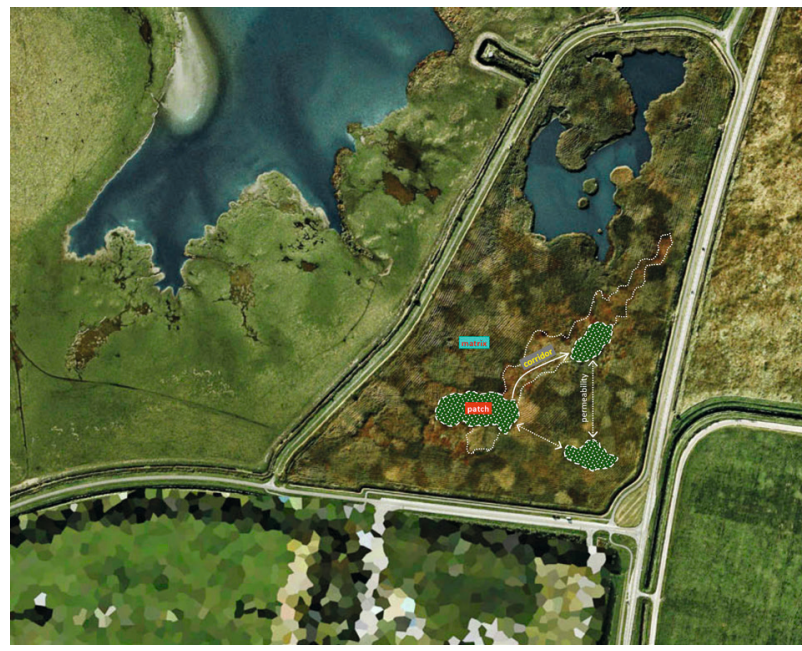

Figure. Landscape mosaic and its components identified on a fragment of Mishka Henner's 'Willem Lodewijk van Nassau Kazerne, Vierhuizen, Groningen' (diagram by the author). Source: Dutch Landscapes series (Henner, 2011).

\section{Part 2. Dwelling: planet as human habitat and its state}

\section{Nature, man: ecosystem services}

In prehistoric times, humans started adapting the natural habitat in order to dwell more comfortably in it (Rossi, 1982, p. 21). By that, marking the transition from nomadism to sedentarism, the start of the agricultural revolution, and, along with it, the rise of its inseparable other, the urban civilization, that is, the world of those who dwell. That primeval, self-aware modification of the surrounding space also coincides with the initiation of a rational mind that splits from the sphere of the instincts (Henderson, 1978, pp. 120-128). The change of perspective from instinctual to rational through which humans have severed from nature has produced disruptive impacts engendering a discontinuity in the evolution of the biosphere.

We are all incrementally exposed to the catastrophic consequences of the exclusive adoption of an anthropocentric, predatory vision of the world. We have previously advocated for the necessary destabilization of our perspective (Pasini, 2019, p.
179). To adopt the poetic and militant definition of Pope Francis' encyclical letter Laudato si', we need to tune up our vision with the multiplicity of the guests with whom we are sharing this "common home" (Francis, 2015).

However, for centuries, we have been defining nature in reference to human presence, which we now discover as being hideously invasive. By nature, we have been referring to the planetary ecosystem as it were man's habitat, a humongous patch covering the surface of Earth in which humans dwell. As we saw, a habitat is equally composed of abiotic components and biodiversity, that is, non-living formations and living organisms, or biota, which conjure up the scenery for the interplay of the human population. Humans have recognized the stocks of biota and non-living components useful to provide for their material needs, such as food or minerals, the energy stocked in fuels or flowing in processes. They have as well recognized the intangible qualities of certain formations favoring their psychological wellbeing, such as a panorama or the sound of the waves. These material and immaterial components have been labeled under the anthropocentric term of 'ecosystem services.'

Ecosystem services are conventionally classified into four categories following the Millennium Ecosystem Assessment run under the aegis of the United Nations in the period 2000-20054

4 The Millennium Ecosystem Assessment (MA) is a foundational characterization of the state of natural ecosystems and biodiversity on Earth, consequently determining urgent targets to recalibrate mankind/nature equilibrium. Unaccomplished ambitions have been further articulated in the Strategic Plan for Biodiversity 2011-2020 and the Aichi Biodiversity Targets of the Convention on Biological Diversity of 2010 and following sessions until 2018 (cbd. int). The 2015 UN Sustainable Development Summit has adopted an overall reprogramming of the targets as the 2030 Agenda for Sustainable Development. The European Union Biodiversity Strategy to 2030, elaborated in a series of reports starting in 2013, initially targeting 2020, is ongoing under the Mapping and Assessment of Ecosystems and their Services (MAES) program (biodiversity.europa.eu/maes). The MAES 
(Salomon, 2009, p. 24; Brauman and Daily, 2009, p. 27; Balvanera et al., 2017, p. 44). Supporting services such as soil formation, primary production from photosynthesis, nutrient cycling, filtration of ultraviolet radiation, seed dispersal, and maintenance of biodiversity constitute an underlying basis of the overall system. From provisioning services, humans supply themselves with material stocks and energy sources such as freshwater, food, various materials, and fuels. From regulating services, such as air and water depuration, soil fertilization, climate mitigation, and pollination, humans benefit for their countless actions mitigating environmental conditions. Cultural and aesthetic services provide opportunities for psychological relaxation and recreation through contemplation and exploration, while favoring the consolidation of group identity (MA, 2005, p. 40).

Despite partial observations proliferating worldwide and rough estimates calculating the planetary ecosystem services as worth twice the world's gross product (Salomon, 2009, p. 24), the mapping of these vital benefits remains to date mostly incomplete due to fragmentation of datasets and heterogeneous quantification systems (Balvanera et al., 2017, p. 43). Consequently, the extent to which these benefits are in existence (supply) has been determined with some approximation only for few and most manifest categories, as the extent to which they are being consumed (delivery), usually to the short-term convenience of humans regardless of renewability factors. However, the latest assessment of planetary ecosystem services is contained in The Global Assessment Report on Biodiversity and Ecosystem Services released in 2019 by the Intergovernmental Science-Policy Platform on Biodiversity and Ecosystem Services (IPBES), an independent intergovernmental body established by States to coordinate efforts on the

constitutes the most coherent and effective regional contribution to the efforts of the Intergovernmental Science-Policy Platform on Biodiversity and Ecosystem Services (ipbes.net), an intergovernmental entity created to assess the state of nature relative to human activities. assessment of the state of nature in relationship to humankind. ${ }^{5}$

In the last fifty years, the human population has grown 2.6 times, from 3 billion in 1970 to 7.7 billion in 2019. Conservative estimates project its number up to 9.7 billion by 2050, to level off at about 10.9 billion by 2100 (UN Population Division, 2019, p. 5). In the same interval 1970-2019, humankind's provision demand, represented by the world's gross product, has inflated 4.2 times, ${ }^{6}$ well over linear proportionality, due to increasing living standards. On the one hand, this is a consequence of the enhancement of material living standards of certain social groups in developing countries, on the other hand, of the multiplication of the perceived needs of individuals globally. This trend is projected to accentuate steadily until the end of the century: by 2050 , the human population is expected to grow by $20 \%$ while the world's gross product by $300 / 600 \%$ (MA, 2009, p. 2).

The current management practices, through which countless services are exploited well over renewability rates, represent an unsustainable burden on natural ecosystems.

\section{Biosphere, anthroposphere}

Biogeography interprets the planetary distribution of natural ecosystems, species assemblages, and related inorganic formations, across geological time. In the 1990s, the World Wildlife Fund backed a study with the ambition of identifying, classifying, and mapping the characteristic ecological assemblages on Earth. The study explores the ecosystems of the biosphere, emphasizing the value of its biodiversity and the scientific retracing

5 IPBES' final aim is favoring conservation and sustainable use of natural resources and long-term sustainable development.

6 World's gross product in US dollars has increased by about 29 times from 2.96 to 85.93 trillion USD (worldbank. org) while living cost has increased by about 6.9 times (bls. gov), yielding a 4.2 factor of gross product increase. 
of environmental conditions prior to major human impact (Olson and Dinerstein, 2002).

From previous scientific hypothesis, ${ }^{7}$ the study assumes the frame of a macro-subdivision of the surface of Earth into eight biogeographic zones ${ }^{8}$ of continental scale and adopts the notion of biome, that is, a characteristic ecological environment recognizable across the boundaries of the macrosubdivision. The study then classifies twenty-six of these biomes distributed in the terrestrial, freshwater, and marine realms: respectively fourteen, seven, and five. ${ }^{9}$ The authors eventually proceed to the identification and georeferenced mapping of a total of 867 specific ecoregions, nested within the realm level, the biogeographic level, and the biome level. Through criteria such as taxonomic richness, endemism, rarity of extant stock, and reduced size of surviving patches, ${ }^{10}$ intactness, and exemplary representation of specific biomes, a set of ecoregions can be selected as priority targets for nature conservation actions. The final aim of the determination of priority-target ecoregions is that of safeguarding planet Earth's paramount value of biodiversity $^{11}$ (Olson and Dinerstein, 2002, pp. 207-210, 218).

The Millennium Ecosystem Assessment assumes that eight of fourteen terrestrial biomes have

7 The authors credit R.F. Dasmann's 'Biotic Provinces of the World' (1974) and M.D.F. Udvardy's 'World Biogeographic Provinces' (1975).

8 Through the study, these biogeographic zones are at times referred to as realms. The term should not be confused with the notion of terrestrial, freshwater, and marine realms, consistently deployed by the authors.

9 The total number of biomes is 26, despite unclear references to a total of 30 biomes (Olson and Dinestein, 2002, p. 200). However, the classification of terrestrial biomes is deemed exhaustive, while freshwater and marine environments are presented as liable for further articulation.

10 Scarcity of total stock and limited size of patches are due to habitat destruction and fragmentation, respectively.

11 Adopted by the World Wildlife Fund under the name of Global 200 project, the study has become the blueprint for environmentalist action to date. been lost for $40-70 \%$ of their original surface in the course of history (MA, 2004, p. 4). In no small measure, their conversion has been in favor of agricultural production and, in minor proportion, of urbanization. Also, fifteen of twenty-four fundamental ecosystem services classified ${ }^{12}$ are in a degraded and declining state (MA, 2004, p. 7). On the one hand, the risk of further conversion of Mediterranean and temperate biomes ${ }^{13}$ is estimated as limited, in the face of reforestation actions being implemented in the European Union and North America. On the other hand, the expansion of human activities has shifted onto tropical, subtropical and coniferous biomes ${ }^{14}$, the geographic territories of the developing economies, where additional loss of surface by 2050 is expected to reach up to $30 \%$ with consequent damage of the related ecosystem services (MA, 2004, p. 32). The mentioned IPBES report of 2019 synthesizes the state of planetary ecosystem services through an even bleaker assessment of primal 'contributions of nature to people', where fifteen of eighteen parameters exhibit recent further decline ${ }^{15}$ (IPBES, 2019, p. 23).

12 These include capture fisheries, wild food, wood, genetic resources, biochemicals, freshwater, air quality, water quality, local climate regulation, natural hazard regulation, erosion, pest regulation, pollination, spiritually valued natural assets, and aesthetically valuable natural ensembles.

13 Mediterranean forests, woodlands, and scrub; temperate forests, steppe, and woodland; temperate broadleaf and mixed forests.

14. Tropical and subtropical dry broadleaf forests; flooded grasslands and savannas; tropical and sub-tropical grasslands, savannas, and shrublands; tropical and sub-tropical coniferous forests; montane grasslands and shrublands; tropical and subtropical moist broadleaf forests; temperate coniferous forests.

15 These are habitat formation and maintenance, pollination and seed dispersal, regulation of air quality regulation, freshwater quality, climate, ocean acidification, soil formation and maintenance, natural hazard mitigation, pest control, biochemical and genetic resources, inspiration, psychophysical experience, identitarian ensembles, biodiversity, with the only exceptions of energy, food, materials, which have been recently showing virtuous trends. 
The footprint of human activities has impacted natural biomes up to the point that the notion itself survives mainly as an ideal reference and, along with biomes, the entire geosphere has been impacted. The International Geosphere-Biosphere Programme, a long-term ponderous study of the International Council for Science, reconstructs the ecological dynamics of the geosphere, or planetary machinery, prior to significant human influence (Steffen, 2004, pp. 11-80). Formal procedures are underway for the adoption of the Anthropocene in the geologic time scale as the epoch dating from the manifestation of major human impacts on the natural metabolism of the Earth. Clear traces are embedded in the geology of the planet. The International Geosphere-Biosphere Programme identifies the starting point of the Anthropocene with the advent of the Industrial Revolution in the late $18^{\text {th }}$ century ${ }^{16}$. The society of the anthropocene is based on fossil-fuel energy systems and characterized by an increased technological capacity to extract, consume, and produce, entailing an enormous rise in the human population. However, the graph of the world's Real Gross Domestic Product reflects an even greater, exponential increase in global consumption in the post-WWII period due consumption intensification beyond population growth, in line with the trends of production and emissions of copper, lead, and zinc (Steffen, 2004, pp. 81-84). Conventionally referred to as the Great Acceleration, the mid- $20^{\text {th }}$ century concurrent increase of socioeconomic and ecological trends is captured by a series of graphs mapping change from 1750 onward (Steffen, 2004, pp. 132-133).

Biologists propose that the ubiquitous influence of human activities has generated an own realm within the geosphere, acknowledged under the denomination of Anthroposphere. The Anthroposphere has emerged while decoupling from the general biotic ambit of the biosphere, alongside

16 The determination of the starting point of the Anthropocene is debated, with hypotheses ranging from the early agricultural revolution in prehistoric times to the postwar period (Ellis, 2018). the abiotic ambits of the Atmosphere, Lithosphere, and Hydrosphere. The notion of Anthroposphere is as expansive as to embrace the entire geosphere within an anthropocentric perspective.

Technocratic approaches lead to the conviction that the scientific knowledge of the metabolism of the Anthroposphere can gain direct control over the metabolism of the entire planet. Environmental engineers and urban metabolism specialists have applied to the study of built territories the methods of material flow analysis traditionally adopted for ecological systems (Baccini and Brunner, 2012, p. 1). The underlying hypothesis is that of modeling the flows and stocks of matter, energy, and information relative to the natural/artificial metabolism of large territorial compounds, regarded as hybrid human/ecological systems (Baccini and Brunner, 2012, p. 81).

A simultaneously neo-positivistic and visionary stance, this work casts scenarios of a gradual diffusion of the agency of planning, designing, and transforming space into a collective, impersonal regulatory system. The natural/artificial space is framed in a pyramidal structure pivoting on the vertices of geo+bio-sphere, built infrastructure, business world, institutions. Spatial change is negotiated through policies enacted on air-watersoil, facilities management, materials and energy, science and environment, landscaping and territorial development, as well as economy (Baccini and Brunner, 2012, p. 283).

\section{Relational Landscape Systems vs. Unlimited Growth Model}

Similar attitudes are adopted by environmental scientists advocating for a non-catastrophic ecological perspective on the ongoing disruptions of the geosphere. They rely on the neo-positivistic confidence in the incremental scientific knowledge and technological know-how available to humankind to govern ecologic changes (Ellis, 2014). Such perspectives have proven functional to pseudoecologist movements in the disciplines of spatial 
design such as Landscape Urbanism. Combining references to geophilosophical thinking and terminology with the idea of controlling the metabolism of the natural/artificial machinery, Landscape Urbanism has gained hegemony in North American and European academia and influenced the practice world. The High Line linear park in Manhattan is an exemplary implementation of such a posture, generating one of the most exclusive metropolitan corridors of the world. Sustainable-looking landscape compositions along a vacant rail line converted into an elevated pedestrian path produce sophisticated aesthetic effects. Nonetheless, the intervention ends up perpetuating the unlimited-growth model unfolding in massive luxury edifications on both sides of the vegetated strip.

While spiraling through the expansion of habitat destruction and intensification of production, the unlimited-growth model has been unloading its burden of refuse onto the geosphere. Natural biomes have been replaced by new entities defined by some anthromes (Ellis, 2014), to boldly mark the new hybrid metabolism of natural and artificial components instated by humankind. Others, in a more subtle perspective, have referred to these entities as socio-ecological systems (Winkler et al., 2018) to emphasize their relational essence, interlinking natural ecologies and socio-economic systems through multiple levels of tangible and intangible variables.

The notion of socio-ecological systems focuses on the dynamics between an ecosystem and the human group that colonizes it, by that, combining metabolic entendment and cultural reading. The characterization of socio-ecological systems has been recently pursued through a scholarly, systematic review of pertinent literature that compiles a classification of characteristic variables (Winkler et al., 2018, p. 138). An unaware collective movement appears to emerge from the review when multiple independent research efforts converge towards a coherent construct of 'land system'. The characteristic variables of the construct are organized in a hierarchical scheme with a primary subdivision between the spheres of built/natural environment and human society. On the one hand, environmental variables are further articulated on a lower tier into the categories of 'physical', 'biological', and 'landscape', on the other hand, social variables break down into 'economic', 'demographic', 'health', 'political', and 'cultural' (Winkler et al., 2018, pp. 138-139).

Among these categories, of particular interest is that of 'landscape', composed by the subcategories of 'composition' and 'configuration'. Here, the former term stands for the land use distribution imposed by man and the latter term for the spatial arrangement of different recognizable features (Winkler et al., 2018, p. 139). By pointing again at the coexistence of metabolic and cultural exploration of the surrounding space, the composition/ configuration binary characterizes a contemporary landscape construct furthermore.

This is, however, a contemporary notion that has its roots in the rise of Western modernity. It is the modernity brought forth by the artieri, the novel craftsmen of the Humanism (Camporesi, 2016, p. 21 ). Both engineers and artists, these hybrid figures journeyed across the Italian peninsula, contended between competing seignories, to prospect the features on the surface of the land that revealed precious mineral deposits down in the geologic depths of the earth. Those prospections, both pictorial and technical, surfaced both the figures and materials that would incarnate the Renaissance. Furthermore, the interface established between the figurative manifestations on the surface and the environmental mechanics in the depths would yield the modern notion of landscape (Camporesi, 2016, pp. 24-25).

The very denomination of 'land system' restores afresh that original idea, one that stands at the etymological root of the English term landscape, as well as its neo-Latin equivalents paysage, paesaggio, paisaje, (Camporesi, 2016, p. 5) by evoking the human gaze unfolding over and into 
the land. It is, then, a modern and ancient notion of landscape, linked to a modern and ancient notion of modernity that has been evolving for about five centuries. That idea of landscape, or land system, is incarnated in the magnificent Tableau fisique des Andes et des pays voisens, that encompasses in an overall vision the observations from Alexander Von Humboldt and Aimé Bonpland's voyage to the equinoctial regions at the turn between the $18^{\text {th }}$ and $19^{\text {th }}$ centuries. By combining scientific notations and figurative captures, in fact, the tableau condenses the ambition to a holistic vision of the laws of nature that link the physical mechanics of the planet with the figurative manifestation on its surface (Humboldt and Bonpland, 2009).

\section{Conclusions: an agenda to revert the crisis}

\section{Present state}

Five data extracted from the IPBES assessment of biodiversity and ecosystem services synthesize the current state of the planet: extensive environmental degradation, with $75 \%$ of terrestrial environment severely altered by human actions; broad ecosystem destruction, with $47 \%$ reduction of ecosystem extent and condition, ongoing at a current $4 \%$ decline rate per decade; increasing global consumption of materials by a $4 \%$ rate per decade; water quality degradation, with $80 \%$ of global wastewater discharged untreated; growing disposable productions, with a 2.5 -time increase of plastic pollution per decade (IPBES, 2019, pp. 28-33). The data describe, on the one hand, increasing environmental degradation and destruction for human occupation coupled with increasing resource depredation for human delivery, on the other hand, increasing unsustainable productions for short-term human utility. These trends solely reflect human activities perpetuating a model of dwelling based on the principle of unlimited expansion.
The Millennium Ecosystem Assessment of 2005 had determined a set of primary targets to recalibrate humankind/nature equilibrium. The targets had been further articulated in the Strategic Plan for Biodiversity 2011-2020 and Aichi Biodiversity Targets of the Convention on Biological Diversity of 2010 (cbd.int). From the overall picture resulting from the report, the Aichi Biodiversity Targets have mainly been missed (IPBES, 2019, pp. 14-15). In consideration of the poor progresses achieved, (IPBES, 2019, pp. 34-36) even the reprogrammed 2030 Agenda for Sustainable Development adopted by the 2015 UN Summit appears today highly implausible, unless groundbreaking changes transforming the economic, social, political, and technological status quo (IPBES, 2019, p. 33).

\section{Six imperatives}

With the anthropogenic disruptions of the geosphere reaching a point of no-return, a sixth planetary mass extinction event is looming, after the five events conventionally counted by geology (Raup and Sepkoski, 1982). Through such events, the Earth has always been capable of regenerating itself into a new biodiversity regime and new forms of life in the eternal scale of its geologic history (Greshko, 2019). In this case, however, the human species might be the only cause and a victim among many others. Six concise imperatives emerge, then, to ensure a future to the human species. Concisely formulated below in conclusion of this paper, the imperatives relative to the spheres of cognition, demography, economy, equality, ecology, and built environment, are intended to strike a new balance between nature and human dwelling.

1. Cognition: Aim at a holistic understanding of the surrounding environment capable of capturing metabolic and cultural values.

2. Demography: Enact measures of demographic programming to reduce the human population on the planet to a total of 3-to-4 billion individuals. 
3. Economy: Convert economy from unlimitedgrowth to circular models, contributing to an overall containment of consumption.

4. Equality: Rebalance the standards of individual consumption across economies, contributing to a less divided distribution of wealth.

5. Ecology: Promote natural conservation and restoration projects to prevent further loss of natural biodiversity and let the biosphere recuperate an autoregulated trajectory of evolution.

6. Built Environment: Ban new constructions and start generating value by removing and retrofitting the extant bulk of anthropic structures and infrastructures.

\section{The tasks of everyone}

The simple considerations above oblige every individual in their personal life as much as every governing institution of any level to unpostponable drastic measures, independently and in collaboration. We are called to urgently apply micro and macro-changes in our realities, ranging from daily habits of personal life to planetary policies. The main targets of global programs must focus on environmental conservation and restoration, on the one hand, and reduction of human productions with conversion to circular models, on the other hand. However, the implicit, all-underlying issue has been resting for over two centuries in the accelerating expansiveness of dwelling that characterizes modern human societies vis-a-vis nature, which has to be brought to a new balance.

\section{References}

Baccini, P. and Brunner, P. (2012). The Metabolism of the Anthroposphere. Cambridge: The MIT Press.

Barrett, G.W., Barrett, T. L., Wu, J. (eds). (2015). History of Landscape Ecology in the United States. New York: Springer.

Balvanera, P. et al. (2017). Ecosystem Services. In: Walters M., Scholes R.J. (eds) The GEO Hand- book on Biodiversity Observation Network. Cham: Springer, pp., 39-87.

Brauman, K. and Daily, G. (2009). Ecosystem Services. In: Jørgensen S.E. (ed) Ecosystem Ecology. Amsterdam: Elsevier B.V., pp. 26-33.

Camporesi, P. (2016). Le belle contrade. Nascita del paesaggio italiano. Milano: Il Saggiatore.

Collinge, S.K. (2009). Ecology of Fragmented Landscapes. Johns Hopkins University Press.

Couper, P. (2007). Fluvial geomorphology and semiotics: a Wittgensteinian perspective of the 'divide' between human and physical geography. In: Transactions - Institute of British Geographers, (32), pp. 272-294.

Ellis, E. (2018). Anthropocene: A Very Short Introduction. Oxford: Oxford University Press.

Ellis, E. (2014). Ecologies of the Anthropocene. Global Upscaling of the Socio-ecological Infrastructures. In: Ibañez D., Katsikis N. (eds) Grounding Metabolism: New Geographies,(6). Cambridge: Harvard GSD, pp. 20-27.

Farina, A. (2009). Ecology, Cognition and Landscape. New York: Springer.

Fath, B. (2009). Ecosystem Ecology. In: Jørgensen S.E. (ed) Ecosystem Ecology. Amsterdam: Elsevier B.V., pp. 6-11.

Forman, R.T.T. (1995). Land Mosaics: The ecology of Landscapes and regions. Cambridge: Cambridge University Press.

Francis. 2015. Encyclical Letter Laudato Si' of the Holy Father Francis on Care for our Common Home. Vatican City: Vatican Press.

Greshko, M. (2019). What are mass extinctions, and what causes them? The National Geographic, September 26.

Henderson, J.H. 1978. Ancient Myths and Modern Man. In: Jung, C.G. et al. (eds) Man and His Symbols. London: Picador Books Ltd, pp. 95-156.

Henner, M. (2011). Dutch Landscapes. Manchester: Open edition. 
Humboldt, A. V. and Bompland, A. 2009. Essay on the Geography of Plants. Chicago, London: The University of Chicago Press.

IPBES (2019). The Global Assessment Report on Biodiversity and Ecosystem Services. Summary for Policymakers. Bonn: IPBES Secretariat.

MA (Millennium Ecosystem Assessment) (2005). Ecosystem and Human Well-being: Synthesis. Washington, DC.: Island Press.

Olson, D. and Dinerstein, E. (2002) The Global 200: A Representation Approach to Conserving the Earth's Most Biologically Valuable Ecoregions. Annals of the Missouri Botanical Garden, (89), pp. 199-224

Pasini, R. (2019). Landscape Paradigms and Posturban Spaces: A Journey Through the Regions of Landscape. Cham: Springer.

Raup, D. M. and Sepkoski, J. J. (1982). Mass Extinctions in the Marine Fossil Record. Science, New Series, 215 (4539), pp. 1501-1503.
Rossi, A. (1982). The Architecture of the City. Cambridge: The MIT Press.

Steffen, W. et al. (2004). Global Change and the Earth's System: A Planet Under Pressure. Berlin, Heidelberg, New York: Springer The IGBP series.

Winkler, K. et al. (2018). A Classification to Align Social-ecological Land Systems Research with Policy in Europe. Land Use Policy, (79), pp. 137-145.

Salomon, A. (2009). Ecosystems. In: Jørgensen S.E. (ed) Ecosystem Ecology. Amsterdam: Elsevier B.V., pp. 16-39.

United Nations (2019). World Population Prospects 2019: Highlights. United Nations, Department of Economic and Social Affairs, Population Division. 